\title{
PENINGKATAN PENGETAHUAN DAN KETERAMPILAN MASYARAKAT TUKANG TENTANG DISAIN DAN KONSTRUKASI ATAP SENG BERBASIS BAJA RINGAN
}

\author{
Heindrcih Taunaumang \\ Universitas Negeri Manado \\ heintaunauman@unima.ac.id
}

\begin{abstract}
Abstrak
Perkembangan penggunaan material/bahan bangunan rumah dengan menggunakan atap seng berbasis baja ringan semakin pesat karena dengan menggunakan material tersebut lebih tahan lama dan relatif lebih cepat pekerjaan diselesaikan. Namun demikian pengerjaan konstruksi bangunan/rumah/garasi dengan atap seng berbasis baja ringan diperlukan pengetahuan tentang material, disain dan konstruksi serta ketrampilan dalam pembuatannya. Berdasarkan pengamatan kami bahwa, Masyarakat-Tukang di Kelurahan Titiwungen Selatan, Kecamatan Sario Kota Manado kalah bersaing dengan tenaga kerja dari luar daerah dalam mengerjakan konstruksi bangunan/rumah dengan atap seng berbasis baja ringan karena mereka hanya terbiasa dengan mengerjakan atap seng berbasis kayu (konstruksi dengan bahan kayu). Disamping kekurangan tentang pengetahuan disain dan kosntruksi atap seng dengan baja ringan mereka juga belum memiliki ketrampilan serta peralatan seperti bor-elektrik. Dengan demikian mereka kehilangan peluang kerja sehingga sangat berdampak pada masalah ekonomi/pendapatan keluarga. Melalui Pendidikan dan Latihan Kerja merupakan solusi tepat yakni memberikan pengetahuan dan ketrampilan bagi masyarakat-tukang agar mereka boleh bersaing dan mendapat peluang kerja dan akhirnya dapat meningkatkan pendapatan keluarga. Melalui PKM Latihan Kerja ini para tukang (masyarakat) di Kelurahan Titiwungen Selatan Kecamatan Sario Kota Manado telah berhasil meningkatkan pengetahuan dan ketrampilan membuat disain dan konstruksi atap seng berbasis baja ringan. Para tukang (masyarakat) di Kelurahan Titiwungen Selatan Kecamatan Sario Kota Manado menyarankan agar PKM Latihan Kerja ini kiranya dapat di kembangkan untuk pola /disain konstruksi yang lebih variatif.
\end{abstract}

\section{PENDAHULUAN}

\section{Analisis Situasi}

Perkembangan penggunaan material/bahan bangunan rumah dengan menggunakan atap seng berbasis baja ringan semakin pesat karena dengan menggunakan material tersebut lebih tahan lama dan relatif lebih cepat pekerjaan diselesaikan. Namun demikian pengerjaan konstruksi bangunan/rumah/garasi dengan atap seng berbasis baja ringan diperlukan pengetahuan tentang material, disain dan konstruksi serta ketrampilan dalam pembuatannya. Berdasarkan pengamatan kami bahwa, Masyarakat-Tukang di Kelurahan Titiwungen Selatan, Kecamatan Sario Kota Manado kalah bersaing dengan tenaga kerja dari luar daerah dalam mengerjakan konstruksi bangunan/rumah dengan atap seng berbasis baja ringan karena mereka hanya terbiasa dengan mengerjakan atap seng berbasis kayu (konstruksi dengan bahan kayu). Disamping kekurangan tentang pengetahuan disain dan kosntruksi atap seng dengan baja ringan mereka juga belum memiliki 
ketrampilan serta peralatan seperti borelektrik. Dengan demikian mereka kehilangan peluang kerja sehingga sangat berdampak pada masalah ekonomi/pendapatan keluarga.

Kami percaya bahwa melalui Pendidikan dan Latihan Kerjja sebagai solusi tepat untuk memberikan pengetahuan dan ketrampilan bagi masyarakat-tukang agar mereka boleh bersaing dan mendapat peluang kerja dan akhirnya dapat meningkatkan pendapatan keluarga.

Konstruksi bangunan rumah/garasi dengan atap seng berbasis baja ringan ditunjukkan pada gambar 1.

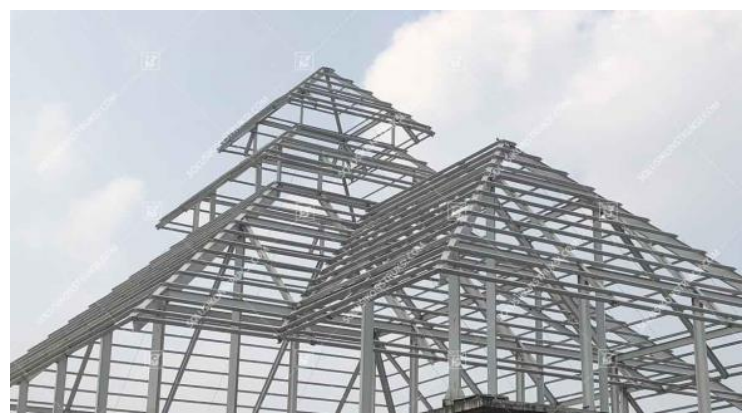

Gambar 1. Konstruksi Atap Seng Berbasis Baja Ringan

Dalam rangka untuk membantu peningkatan pengetahuan dan ketrampilan masyarakat-tukang tentang disain dan konstruksi bangunan dengan atap seng berbasis baja ringan maka sangat diperlukan intervensi Perguruan Tinggi Universitas Negeri Manado dengan program pengabdian masyarakat disamping dalam rangka aplikasi ilmu pengetahuan tetapi juga untuk memberdayakan masyarakattukang sehingga mereka boleh memperoleh pendapatan yang cukup untuk penghidupan keluarga. Pengusul proposal ini sebagai dosen Unima terpanggil dalam memberikan kontribusi nyata memecahkan masalah berkaitan dengan pengetahuan dan ketrampilan tenga kerja lokal.

Berdasarkan pemikiran/analisis situasi yang telah dikemukakan di atas maka penulis ingin mengajukan proposal pengabdian kepada masyarakat pendidikan ini dengan judul : "PKM LATIHAN KERJA BAGI MASYARAKAT - TUKANG TENTANG DISAIN DAN KONSTRUKSI ATAP SENG BERBASIS BAJA RINGAN DI KELURAHAN ITIWUNGEN SELATAN KECAMATAN SARIO KOTA MANADO".

Pengusul proposal ini sebagai dosen Unima terpanggil dalam memberikan kontribusi nyata memecahkan persoalan dalam mengatasi persoalan ketrampilan tenaga kerja di Kota manado khususnya di Kelurahan Titiwungen Selatan, Kecamatan Sario. Kami percaya melalui kegiatan latihan kerja bagi masyarakat-tukang akan berhasil dan bemanfaat karena kerjasama Perguruan Tinggi (Unima), masyarakat kelurahan Titiwungen Seatan, Kecamatan Sario dan pemerintah Kota Manado.

Permasalahan mitra yaitu bahwa Masyarakat-Tukang di Kelurahan Titiwungen Selatan kurang pengetahuan dan ketrampilan dalam membuat disain dan konstruksi bangunan dengan atap seng berbasis baja ringan. Permasalahan mitra ini dirumuskan sebgai berikut: Bagaimana 
disain dan konstruksi bangunan atap seng berbasis baja ringan? Bagaimana menggunakan alat serta membuat atap seng berbasis baja ringan?.

Solusi/pemecahan masalah untuk permasalahan yang telah dikemukakan di atas adalah melakukan kegiatan pendidikan dan latihan kerja pembuatan disain dan konstruksi bangunan atap seng berbasis baja ringan. Untuk itu akan dihadirkan instrukur yang berpengalaman dalam mengerjakan bangunan dengan atap seng berbasis baja ringan.

\section{METODE PELAKSANAAN}

Metode pelaksanaan kegiatan pengabdian ini adalah sebagai berikut:

\subsection{Tahap Persiapan}

- Penentuan lokasi dan waktu pelaksanaan pertemuan/koordinasi dengan Pemerintah Kelurahan Sario Titiwungen Selatan dan MasyarakatTukang Kelurahan Sario Titiwungen Selatan.

\subsection{Tahap Pelaksanaan}

- Persiapan bahan, alat

- Penjelasan/pelatihan pembuatan disain/perancangan dan konstruksi bangunan dengan atap seng berbasis baja ringan.

\subsection{Tahap evaluasi / perbaikan}

\subsection{Tahap pelaporan}

Metode pelaksanaan pengabdian kepada masyarakat ini meliputi tahapan sebagaimana ditunjukkan pada gambar 2 .

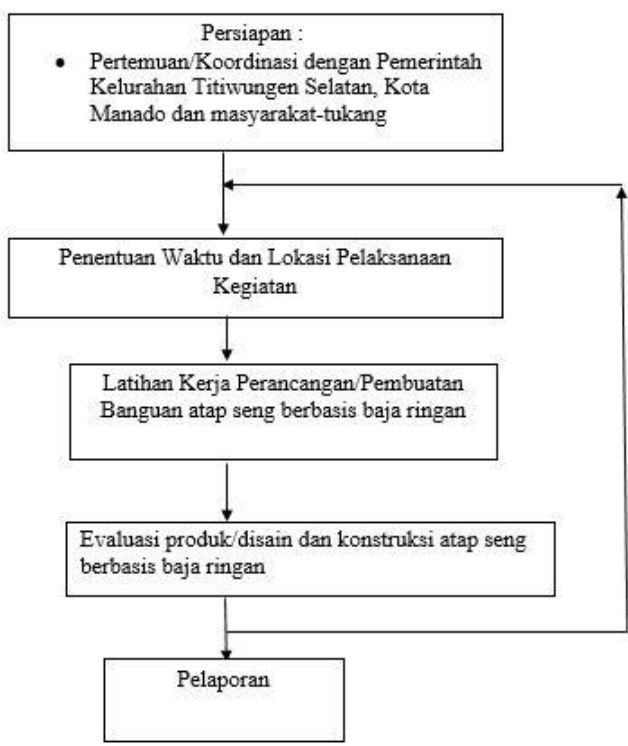

Gambar 2. Skema tahapan kegiatan pengabdian PKM

\section{HASIL DAN PEMBAHASAN}

Kegiatan ini telah dilaksanakan pada hari Jumat, tanggal 14 Juni 2019. Tempat lokasi Kelurahan Titiwungen Selatan Lingkungan 2 Kecamatan Sario Kota Manado. Judul kegiatan PKM ini sebagaimana ditunjukkan pada Gambar 3.1.

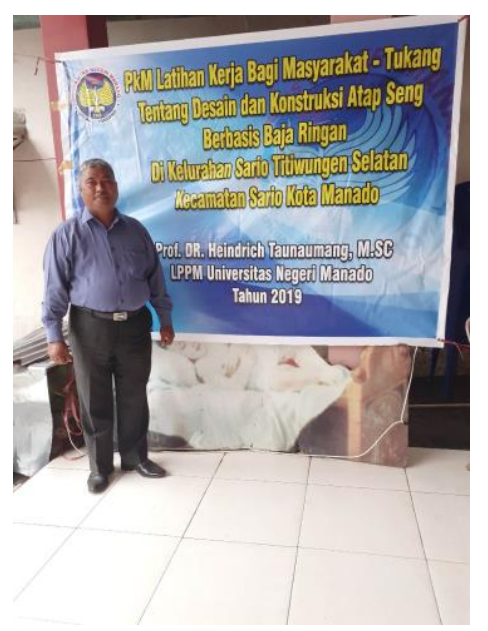

Gambar 3.1. Persiapan kegiatan PKM LPPM Tahun 2019 oleh Prof. Dr. Heindrich Taunaumang, M.Sc. 
Bahan yang telah disiapkan sebagaimana ditunjukkan pada Gambar 5.2.

a. Taso (TS) 150-C75.75 dengan panjang $6 \mathrm{~m}$ dan lebar $7 \mathrm{~cm}$, tebal 3 $\mathrm{cm}$.

b. Taso (MX) 110-R30.45 dengan panjang $6 \mathrm{~m}$ dan lebar 7 tebal $3 \mathrm{~cm}$

c. Seng dengan panjang $185 \mathrm{~cm}$ dan lebar $80 \mathrm{~cm}$.

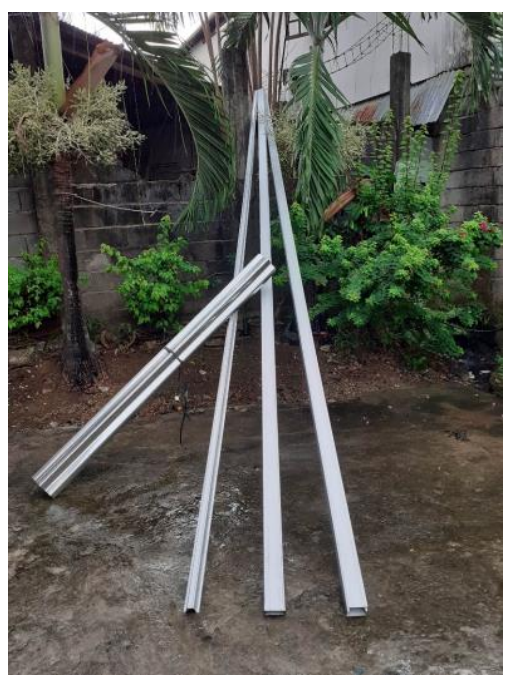

Gambar 3.2. Bahan yang telah disiapkan untuk kegiatan PKM.

Peralatan yang telah disiapkan adalah sebagaimana ditunjukkan pada Gambar 5.3a-5.3g.
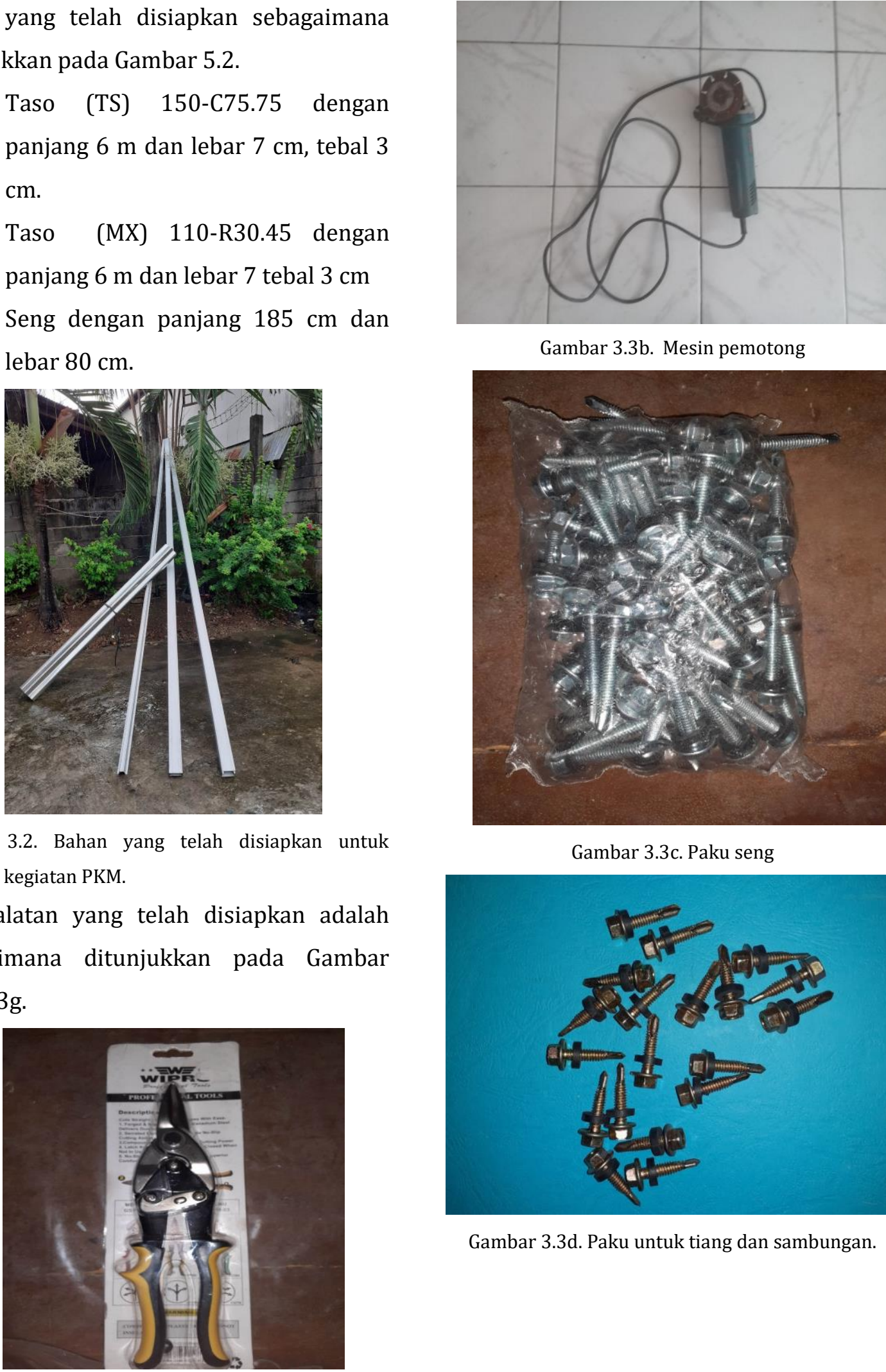

Gambar 3.3b. Mesin pemotong

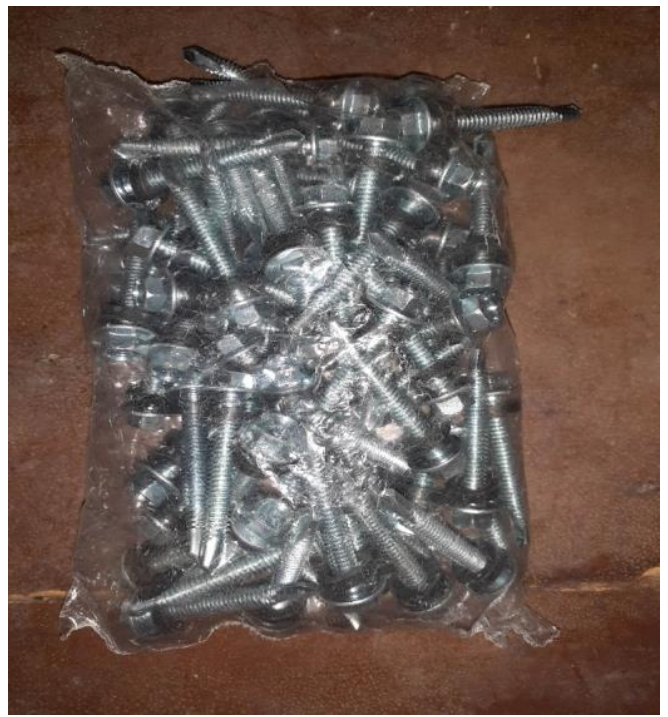

Gambar 3.3c. Paku seng

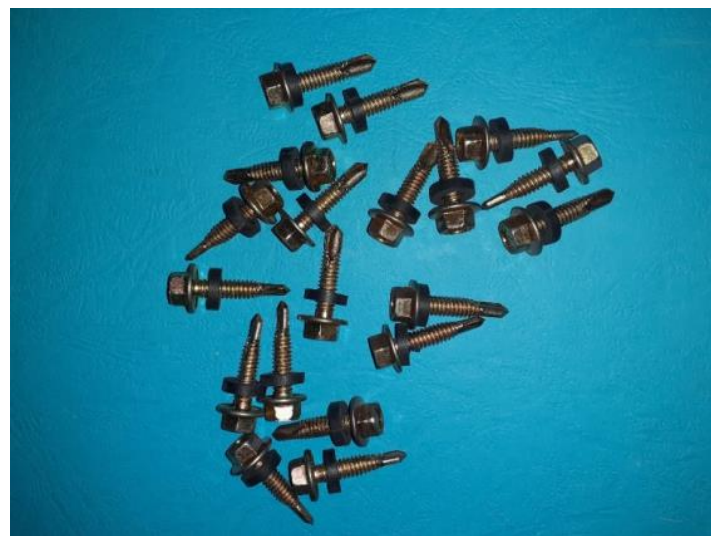

Gambar 3.3d. Paku untuk tiang dan sambungan.

Gambar 3.3a. Cutter. (pemotong) 
Jurnal ABDIMAS, Vol. 12, No. 1, April 2019

ISSN: 1979-0953 | e-ISSN: 2598-6066

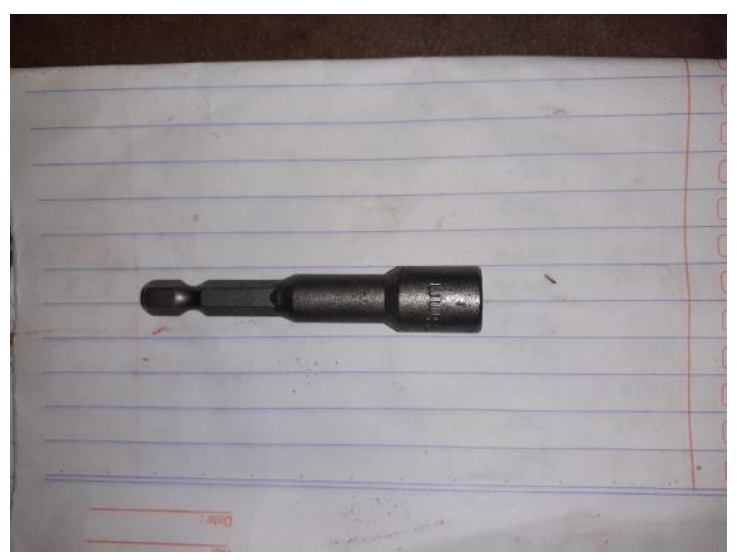

Gambar 3.3e. Komponen pemutar bor

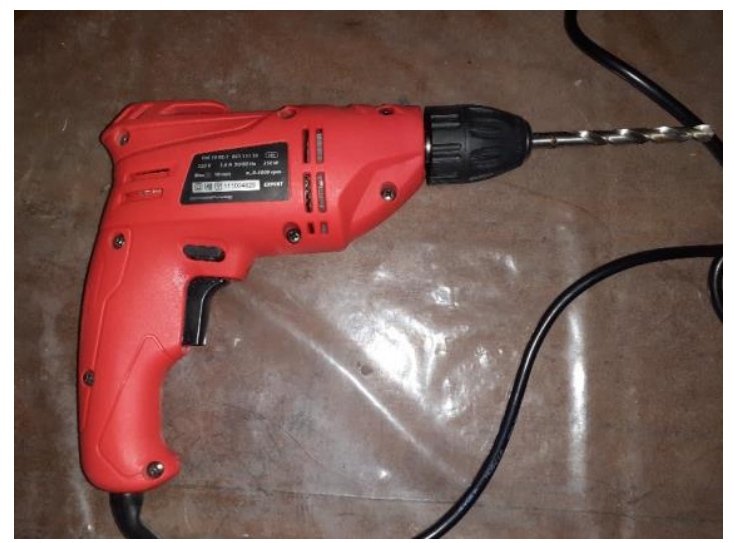

Gambar 3.3f. Bor listrik

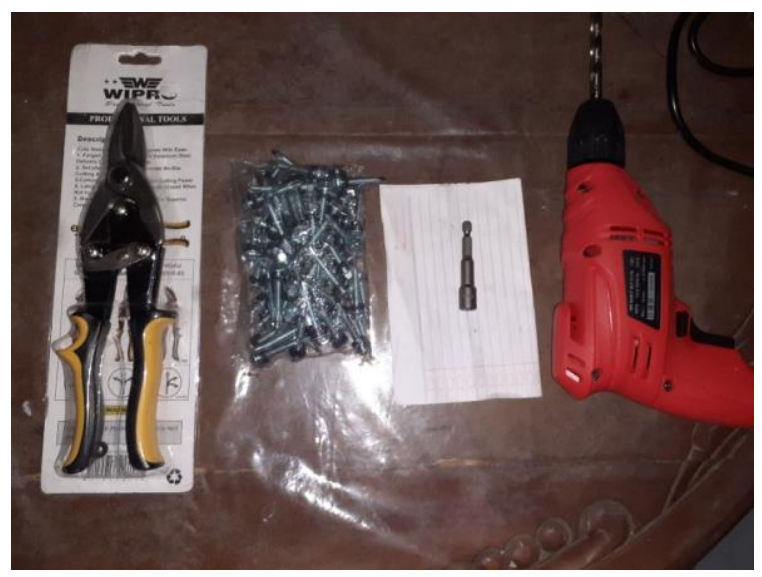

Gambar 3.3g. Peralatan Untuk Pembuatan Atap Seng Berbasis Baja Ringan.

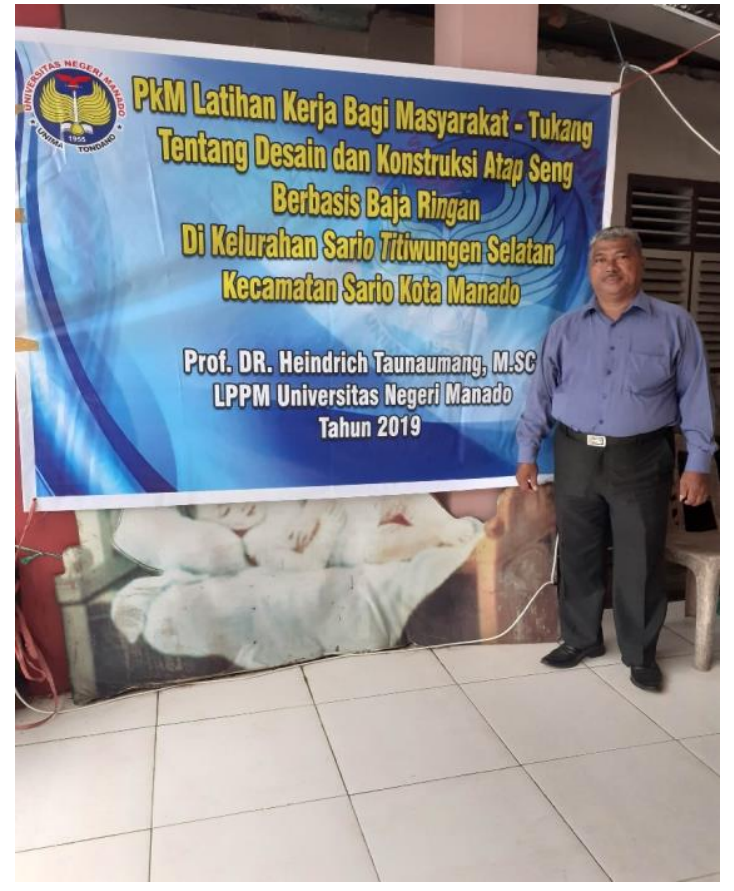

Gambar 3.4. Pengabdi memberikan penjelasan maksud kegiatan PKM

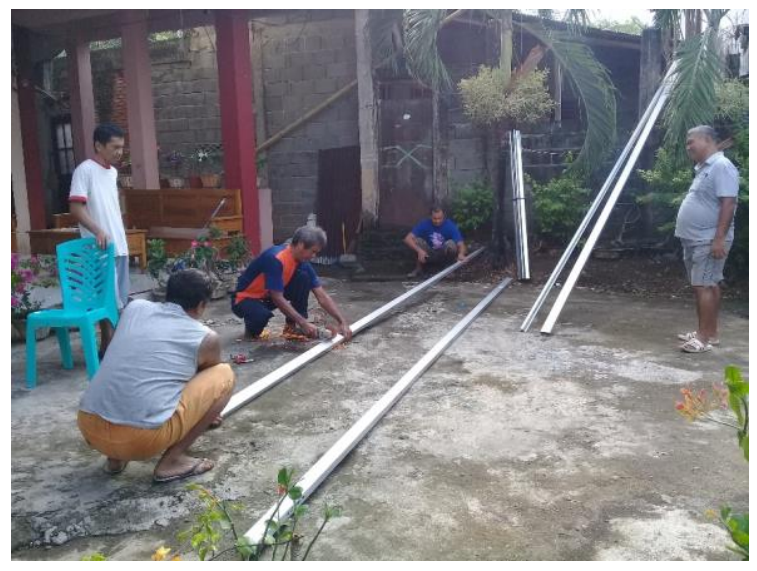

Gambar 3.5. Instruktur mendemostrasikan cara memotong taso (baja ringan) dengan menggunakan pemotong elektrik.Untuk tiang dengan panjang 2 meter.

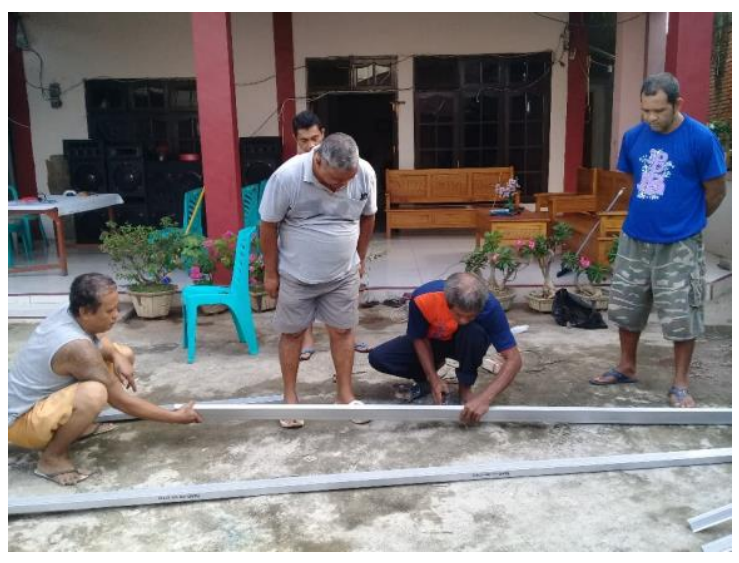


Gambar 3.6. Instruktur mendemostrasikan cara memotong taso (baja ringan) dengan menggunakan pemotong manual. Untuk tiang dengan panjang 2 meter.

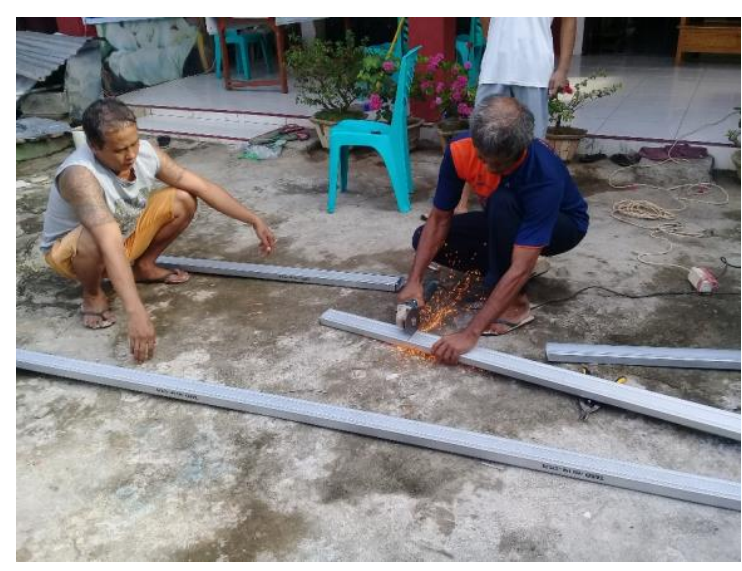

Gambar 3.7. Instruktur mendemostrasikan cara memotong taso (baja ringan) dengan menggunakan pemotong elektrik.Untuk penyela tiang dengan panjang $20 \mathrm{~cm}$.

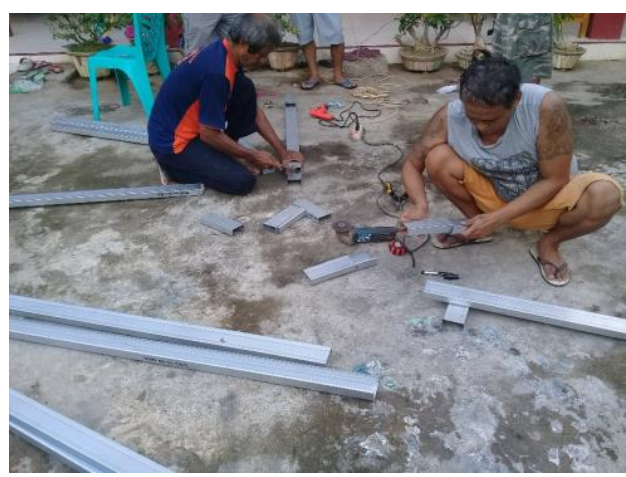

Gambar 3.8. Instruktur mendemostrasikan cara membuat penyela untuk tiang.

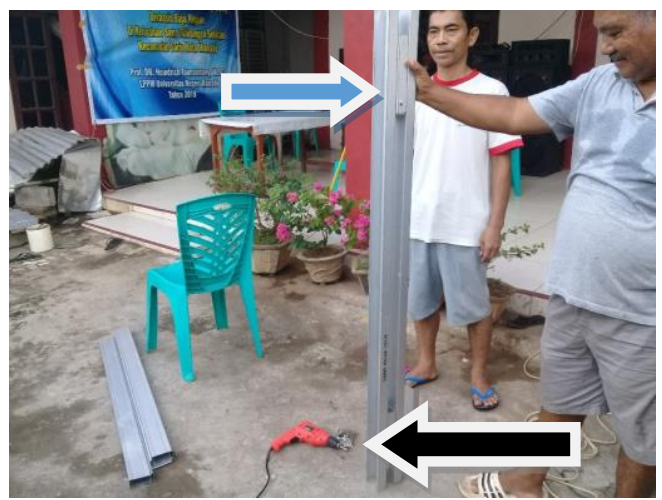

Gambar 3.9. Tiang ganda dan penyela.

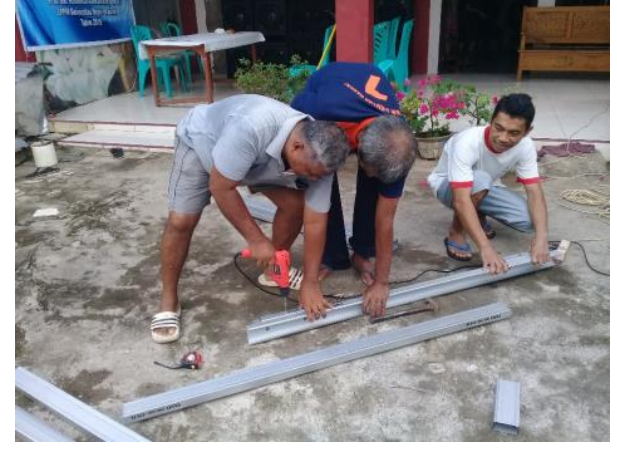

Gambar 3.10. Instruktur membimbing cara memotong menggunakan bor elektrik.

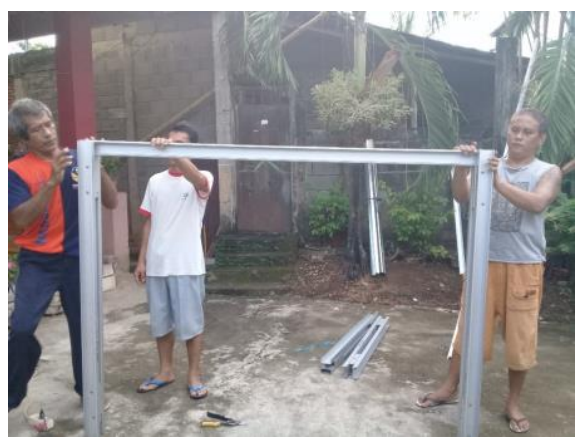

Gambar 3.11. Instruktur mendemostrasikan cara membuat tiang dan penghubung antar tiang.

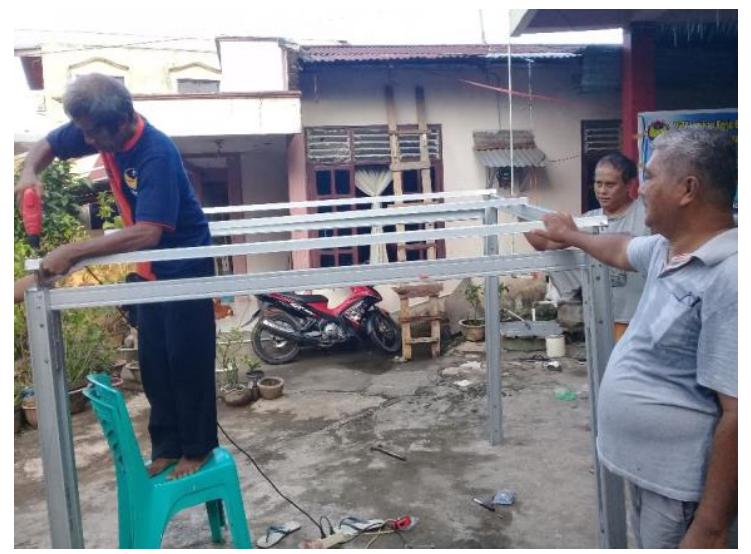

Gambar 3.12. Instruktur mendemostrasikan cara memasang lata dengan memasang paku dengan menggunakan bor elektrik. 


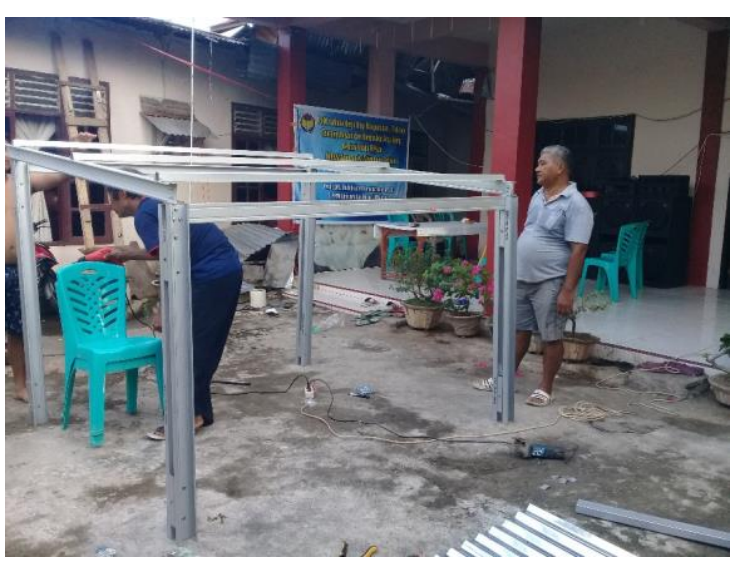

Gambar 3.13. Kontruksi sederhana dengan 4 tiang.

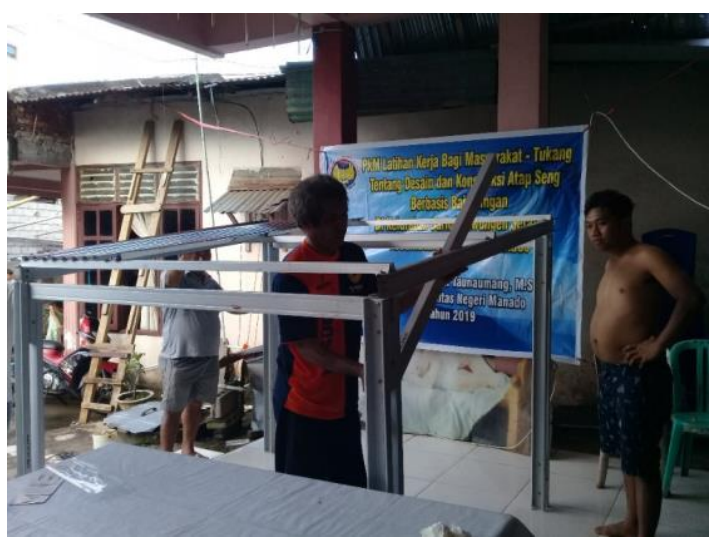

Gambar 3.14. Instruktur mendemostrasikan cara membuat skor (penguatan).

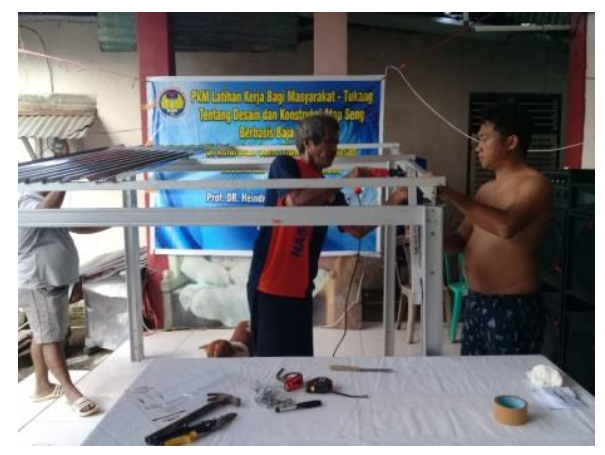

Gambar 3.15. Instruktur mendemostrasikan cara memasang seng.

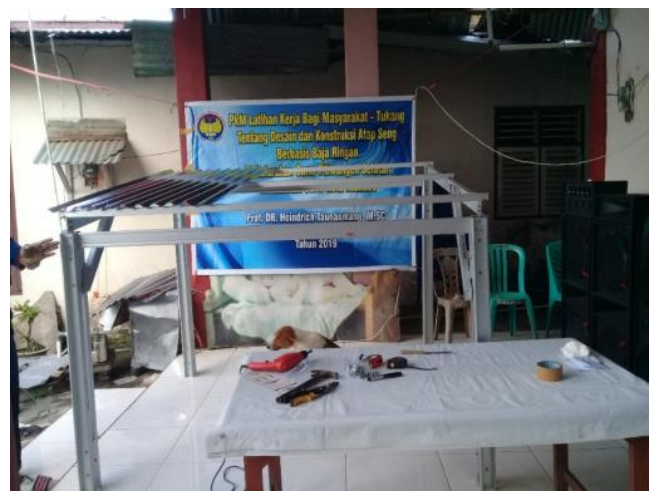

Gambar 3.16. Konstruksi sederahana pemasangan seng berbasis baja ringan selesai.

\section{PEMBAHASAN}

Masyarakat tukang sangat antusias mengikuti penjelasan instruktur tentang :

- Cara memotong taso (baja ringan) dengan menggunakan pemotong elektrik dan dengan gunting. Menggunakan pemotong listrik lebih cepat dibandingkan dengan menggunakan pemotong gunting. Telah diingatkan jangan menggunakan pemotong elektrik saat hujan/basa. Demikian juga untuk konstruksi yang lain. Pelaksanaan pekerjaan tidak dalam dilakukan pada tempat basa (saat hujan).

- Cara merakit dengan menggunakan bor listrik dan paku yang khusus. Perakitan dengan paku, bor listrik perlu ditekan.

- Cara membuat tiang

- Cara memasang lata

- Cara memasang seng

Komentar para tukang bahwa pengerjaan atap seng berbasis baja ringan relatif lebih cepat.

\section{KESIMPULAN DAN SARAN}

\section{Kesimpulan}

Melalui PKM Latihan Kerja ini para tukang (masyarakat) di Kelurahan Titiwungen Selatan Kecamatan Sario Kota Manado telah berhasil meningkatkan 
pengetahuan dan ketrampilan membuat disain dan konstruksi atap seng berbasis baja ringan.

\section{Saran}

Para tukang (masyarakat) di Kelurahan Titiwungen Selatan Kecamatan Sario Kota Manado menyarankan agar PKM Latihan
Kerja ini kiranya dapat di kembangkan untuk pola /disain konstruksi yang lebih variatif.

\section{KEPUSTAKAAN}

https://www.google.com/search?q=konstruk si+baja+ringan+untuk+rumah 